\title{
The Application of BIM as Collaborative Design Technology for Collective Self-Organised Housing
}

Ton Damen, DEMO Consultants BV, Delft, Netherlands

Rizal Sebastian, DEMO Constultants BV, Delft, Netherlands

Matthew MacDonald, Institute for Entrepreneurship and Enterprise Development, Lancaster University Management School, Lancaster, UK

Danny Soetanto, Institute for Entrepreneurship and Enterprise Development, Lancaster University Management School, Lancaster, UK

Timo Hartmann, University of Twente, Enschede, Netherlands

Roberto Di Giulio, Department of Architecture, University of Ferrara, Ferrara, Italy

Peter Bonsma, RDF Ltd., Bankya, Bulgaria

Klaus Luig, 3L Architekten, Menden, Germany

\begin{abstract}
Collective Self-Organised (CSO) housing projects are an emerging trend in Europe. In these projects communities engage in co-design throughout the process. Little knowledge exists that can support CSOs with the process of managing their projects by using state-of-the-art building information (BI) technologies. The authors introduce a BI supported CSO housing design process that can support CSOs through all stages in the design process, from early conceptual location planning through to selection of interior finishing. They illustrate the project using a demonstrative illustration of a CSO housing design process. The paper will concentrate on the development of innovative Collaborative Design Technology (CDT) solutions. The tools will be demonstrated on the basis of an illustrative demonstration case in which the CSO-process is combined with an IFD (Industrial, Flexible and Durable) building system. The particular advantages for architectural design practice will be highlighted throughout and gaps in the literature addressed.
\end{abstract}

Keywords: $\quad$ AugmentedReality, Building Information Modelling, CollaborativeDesign Technology, Concept Modelling, CSO Housing, Participatory Design, Virtual Reality 


\section{INTRODUCTION}

\subsection{The State of the Art of CSO in Europe}

This paper refers to the ongoing EU Framework 7 project PROFICIENT, that deals the development and validation of new processes and business models for the next generation of performance based energy-efficient buildings, which will create business opportunities for SMEs in the construction sector by exploiting the emerging process of Collective SelfOrganised (CSO) housing for the constructing and retrofitting of energy-efficient residential districts. The project addresses the emerging and rapidly increasing trend in Europe of CSO housing.

In a CSO housing process a group of homeowners purchases a piece of land or existing properties; procure professional companies for design, construction and maintenance, and directly manage the project from planning until delivery and use. CSO Housing is a growing market. Recently launched policies and action plans by governments in a number of EU countries indicate a doubling of the current market over the next decade. The demonstration and experimental phase of CSO housing development has proven the value of this concept. For instance, in the Netherlands, in the past 10 years, successful pilot projects in various municipalities across the country have been carried out under the SEV subsidy and supervision programme (SEV, 2010). The UK government claims that "self-build homes are often cheaper, greener, more affordable and more innovatively designed than standard market housing" (DCLG, 2104), and plans for an extra 25,000 self-built homes each year.

\subsection{Problems with CSO Design Processes}

Anumber of barriers and constraints to successful implementation of CSOs have been identified (Gerohazi et al., 2014). As Sebastian et al. (2009) argue, the traditional design and imple- mentation process for housing is fragmented, inefficient and can lead to " $10 \%-25 \%$ loss of efficiency in each project due to unplanned redesigns and ad hoc modifications during the construction. This inefficiency results in delays in the delivery, suboptimal end-product quality, a higher price for the client, and lower revenue for the building participants" (p. 2).

The CSO housing process, however, inserts the client at all stages of design and implementation, not just at initial briefing stages. A further complicating factor is the collective nature of CSO communities and the need for joint decision making between members of a group that may include different members at different stages of the process, as new members join and others leave (Gerohazi, et al., 2014). It is to address these difficulties that the particular Collaborative Design Technology (CDT) model presented in this paper is proposed.

From the SME perspective, as a sector they have the power of knowledge, design, construction and product expertise that ensure the contractor is the gate keeper to successful CSO implementation and the adoption of energy efficiency building (EeB) measures within CSO projects. Adopting Roger's Diffusion of Innovation model (2003), it can be seen that, with the exception of the first adopters and innovators, the other adoption groups cannot be expected to delve into the unknown world of EeB technology without the guidance and expertise of qualified contractors. The first adopters, the innovators, are the only group that could be expected to implement new EeB technologies without the support of government and contractor's expertise. Without the contractors knowledge EeB technology would never be more than a niche market, the majority of the public will find the process too daunting to start alone (Olsson et al., 2004). Further barriers arise due to the iterative nature of the CSO planning process. Time scales of CSO projects can easily outstrip more 'normal' planning and construction processes, as designs are negotiated with community end-users (Gerohazi et al., 2014).

CSO communities, on the other hand, have the power of choice. CSOs often have more 
power than they presume, as the financier of the project it is their money that talks. They are also at the greatest disadvantage, since they do not have the knowledge or experience related to the industry and regulatory experts and the CSO's experience with EeB construction may only occur once in their life. For the CSO the learning curve will be the steepest and often daunting enough to put many otherwise enthusiastic CSOs off the idea completely. Coupled with the great power of finance they are deeply interdependent with the government (where grants and subsidies are available) to motivate the contractor's interest in EeB technology (Olsson et al., 2004; Sebastian, 2006). Governments, both national and municipal, also introduce constraints to the CSO process, through financial, regulatory and policy tools (MacDonald et. al., 2014). By setting the new standards of practice, barriers and constraints can promote or limit the design possibilities available through the use of incentives and penalties (Guy \& Shove, 2000).

The interdependent relationship between the stakeholders, through the government's regulatory power, the SME's expertise and the CSO's financial weight and desire to be fully engaged in the design and delivery, ensures the CSO design and implementation process is complex and uncertain. Sustainable development is dependent on the balance of this power in the decision making process, sustainability requires sustainable relationships (Olsson et al., 2004). The balance of competing demands is essential for successful project implementation.

Efficiency is of the utmost importance to the contractors involved. This is accomplished through the adoption of clear definitions and project scope. Their interest is to provide a quality product, at cost and on time to assure a successfully executed project. Low uncertainty will guarantee that the project is completed within the description of scope, on time and on budget. The long term utility and performance of the building is not of high priority to the contractor as long as they have fulfilled their responsibilities of quality during the construction of the project (Olsson et al., 2004).
Effective results are also of the greatest interest to CSO end-users. As the stakeholders with the greatest personal investment of capital they look for good value and products/services that are low risk. They also have the greatest interest in project flexibility, as flexibility allows a project to be more closely adapted to the needs of the owner as the project progresses. Flexibility during the project helps to guarantee long-term utility but it comes at the cost of project efficiency (Sebastian et al., 2009).

The CSO approach necessitates a change in role and traditional function of these three stakeholder groups. In the traditional approach to urban planning and city development, regional authorities and municipalities dictate top down the priorities, the main structure, the volumes, local zoning plans, what will be build, what it should look like and what target groups are supposed to live there. With CSO projects, however, the situation is considerable different, and to a certain extent upside down. It is a group of individuals that commit, plan, and design the way they want to live. The role of the municipality is reduced to justify and approve the plans, to direct them in the way forward, remind them of formalities, and in the best case negotiate the land. It requires a less descriptive character of planning and procedures.

Traditionally, architects have a commercial perspective on their role in the process. Many of these businesses are not used to working for collective groups of clients, with the participatory design approach this entails. For contractors, suppliers and consultants it is often more complex and demands more explanation compared to regular cases where one deals with professional stakeholders. In a small number of cases the misinterpretation between end-users and contractor has led to conflicts, financial, organisation-wise and/or coordination-wise. As end-users keep on changing their wishes up to the end of the project, and a contractor prefers to have things decided upon as early as possible, this is a great challenge. Many end-users have started the CSO housing process for several reasons, such as ideology, better living quality, social cohesion, environmental reasons etc. 
Almost all have had an unrealistically positive image of the process. (Gerohazi et al., 2014))

Architectural design is the creative industry within the construction sector with a total market value exceeding 15 billion Euros (Mirza $\&$ Nacey, 2008). There are about 550.000 architects in Europe; most of them work in small and medium sized enterprises (SMEs) that have suffered from the recent economic crisis across Europe. To address this, they urgently need to increase their efficiency and competitiveness. One method of achieving this is through the use of new ICT technologies (Evgeniou et al., 2013). PROFICIENT addresses this need by customizing, configuring and demonstrating emerging CDT solutions for architects, especially regarding Building Information Models (BIM), parametric modelling, and Virtual Reality (VR). The technical aspects of the CDT-solutions are summarized in the section on adoption of state-of-the-art CDT solutions.

PROFICIENT will also develop a networked business model to bring the knowledge and tools developed to the target group of European architects and other stakeholders. The business model will focus on the development of a comprehensive and easy to handle platform for provision, learning and exchanging stateof-the-art CDT solutions. An e-marketplace will be part of the platform. The marketplace will allow technology providers to develop and market innovative CDT solutions based upon a combination of BIM, semantic and parametric modelling as well as advanced mobile AR/VR user interfaces. At the same time, the contents of this platform and e-marketplace will be used for embedding CDT solutions in practice and education through Continuous Professional Development (CPD) for professionals and university curricula for architecture students. The proposed business model will be elaborated in the section on the CDT business model and e-marketplace. The CDT tools that will be developed in PROFICIENT will be demonstrated in a CSO/IFD use case, which will be described later in this paper.

\section{ARCHITECTURAL DESIGN AS A SYSTEMIC PROCESS}

The architectural design process can be described as reflective conversation between the individual designer and the design situation (Schön, 1984). According to this concept, designers operate by labelling the parameters of the situation, framing the design problem in a specific way, making observable moves towards the solution, and evaluate these moves. From this perspective, the entire architectural design process can be described as a sequence of design activities, each of which is conducted within a specific frame during which managerial and design decisions are made (Valkenburg \& Dorst 1998; Zerjav et al. 2013). As the design process enfolds these frames are each concerned with different tasks, starting from identifying user requirements for the building(s) to be designed, comparing different configurations of the building to fulfil these requirements, developing specific conceptual designs for a number of chosen configurations, to the final representation of a solution allowing for further discussions with users and providing the input for the subsequent engineering steps based on the configuration method. These steps are repeated throughout the different stages of the architectural design process, from initial urban planning and location selection activities through to the final layout and floor-plan design of buildings.

The above described micro-level design process is interconnected with the management of its organization at the process-level of design (Dorst, 2011; Luck, 2012; Stumpf \& McDonnell, 2002). Therefore, it is not surprising that the above outlined steps of the architectural design process have been strongly institutionalized in the past within norms and guidelines. One of the most stringent and prominent norms is, for example, the German 'Honorarordnung für Architekte und Ingenieure' (HOAI 1999) that defines specific payment cycles for the entire architectural design process. Another example for the use of the implementation of the above steps was conducted within the American 
Institute of Architects (AIA) owner-architect agreements (AIA, 2013).

Recent studies have shown that each of these tasks can be supported by the targeted application of building information models (Hartmann et al. 2008). Many studies have, for example, provided evidence that BIM based visualizations can support communication tasks of designers and can help to develop design knowledge together (Yan et al. 2011; Meza et al. 2014; Heidari et al. 2014). Additionally, the parametric possibilities of state-of-the-art BIM software allows for the quick development and evaluation of design alternatives and for the possibilities to run advanced simulations (Clevenger et al. 2013; Gane et al. 2012; Welle et al. 2014). Many practice based studies of the application of BIM also have shown that to support specific design tasks within specific frames often is unproblematic both from a technological support as well as from a practice perspective. However, supporting the exchange of information from one frame to another frame still poses significant problems (Jernigan, 2008). In practice, these problems more and more manifest as architectural design practice becomes more and more integrated, iterative, and scenario based to account, for example, for energy efficient design requirements (AlQahtany et al. 2013) or to allow for closer participation of the end users within the design process (Sebastian, 2006). Integration of design tasks and their frame, in turn, require better process guidelines for BIM based information exchange.

Because of this requirement it is not surprising that researchers have started to develop a number of integrated process frameworks that map best information exchange practices for various design tasks, such as, among others hospital design (Amstel et al. forthcoming) or subway station design (Hartmann \& Fischer 2007). Despite the rising popularity of CSO housing design, however, to the best of the authors' knowledge, no process framework exists to support this emerging practice. To overcome this gap this paper introduces such a method and discusses an illustrative implementation of the method on a CSO housing project. Before describing this illustration and the method applied for the illustration, the next section introduces the BIM-based CSO design method in detail.

\subsection{Adoption of State-of- the-Art CDT Solutions}

Architecture is broadly acknowledged as the backbone of creativity and the gateway for innovation within the construction sector (Boland et. al, 2007); a sector that is critical to the sustainability of European society and built environment. Construction is the largest European single activity (9.6\% GDP) (Mirza $\&$ Nacey, 2008). Buildings are responsible for $40 \%$ of the total EU energy consumption and CO2 emission (Amstalden et al., 2007).

Architectural design is different from most creative industries, in that it is highly constrained by external social and technical factors. To develop feasible design solutions, architects need to have deep insights into the structural mechanics of buildings, building production techniques, energy performance, functionality of utility systems, organizational processes of building users, construction and exploitation cost, environmental aspects and life span considerations. As a result, architectural design can only be successful if the architect is collaborating intensively with civil engineers, building contractors, component suppliers and most important the client/end-user. To support this collaboration, architects increasingly need the technological support that emerging CDT solutions offer (Petrick et. al., 2002).

CDT solutions can enhance the development of participatory and concurrent architectural design processes. Here, Participatory Design (PD) refers to a design approach, which entails an active involvement of end-users through decision-making processes in the whole design process. During PD processes, CDT solutions allow end-users to focus on the functional and spatial performance of specific architectural design alternatives.

Complementary to participatory design, concurrent design(CD) refers to a direct collabo- 


\section{Table 1. Advantages for architects engaged in CSO of BIM}

\begin{tabular}{|l|}
\hline BIM will shorten the time needed to explore and validate multiple design alternatives; \\
\hline $\begin{array}{l}\text { BIM allows for the visualization of design solutions on a higher level compared to traditional 2D/3D solutions } \\
\text { offering extra competitiveness; }\end{array}$ \\
\hline $\begin{array}{l}\text { BIM will make it possible for architects to integrate information from other disciplines to create a design that } \\
\text { can show the feasibility of meeting the multiple performance demands of a client within the design process (e.g. } \\
\text { energy performance predictions compared to quantified cost estimations can be offered), which is a milestone of } \\
\text { raised competitiveness; }\end{array}$ \\
\hline BIM will reduce potential failure cost by reducing design iterations and more important building defects; \\
\hline $\begin{array}{l}\text { Facility Management software applications can be interfaced with BIM, providing two way data exchange. These } \\
\text { end-user tools are dealing with optimisation of the exploitation and management of real estate. }\end{array}$ \\
\hline
\end{tabular}

ration between professionals in collective design activities to increase possibilities for specialized knowledge sharing and development. Both processes, if organized adequately, can reduce the transaction costs of architectural design processes. CDT solutions support specialist knowledge exchange and generation through increased inter-firm interaction, focusing on the technical aspects related to the feasibility of the building process. They enable the architect to offer new and innovative products, solutions, applications and services. The underlying ICT-technologies (semantic BIM, parametric design, $\mathrm{CMO}$, Virtual and Augmented Reality and BIM-linked end-user solutions) are briefly introduced below.

\subsection{Building Information Modelling (BIM)}

With BIM a new way of modelling for the Building \& Construction industry has been introduced. BIM consists of shared knowledge resources to support decision-making about the building from earliest conceptual stages, through design and construction, through its operational life till demolition. BIM is as such a basic condition for collaborative design and construction.

BIM's object oriented and semantic approach provides a better understanding of what is actually modelled compared to traditional CAD-systems. As a result, the feedback from the software is more detailed and meaningful.
Communication between applications and disciplines is strongly improved. BIM is essential interfacing the design with all kinds of innovative user applications, such as energy performance assessment tools, lifecycle cost calculations, facility management tools, virtual and augmented reality, and geographic and indoor positioning systems (Smith, 2014). The current BIM content is mostly exchanged via the open standard IFC(ISO 16739:2013). Some important drawbacks of this standard are solved via Semantic Web technology form W3C.

The implementation of BIM at an earlier stage of a project (compared to the regular workflow) can benefit architects engaged in CSO developments in the following ways as shown in Table 1.

\subsection{Parametric Design Technology}

Parametric design technology allows the generation of design content from a family of initial parameters and the design of the formal relations they keep with each other. Using these variables to generate a hierarchy of mathematical, semantic, and geometric relations, this allows the exploration of a whole range of possible solutions by varying the values of the initial parameters.

Architects can benefit from implementing the parametric design technology in the following ways as shown in Table 2. 


\section{Table 2. Advantages for architects engaged in CSO of PDT}

\begin{tabular}{l} 
Reuse of models and data in previous projects becomes possible via building up libraries of Parametric Models. \\
Each project is different, but many of the previously used components will share the same concepts. A parametric \\
description potentially reduces repetition of work and makes the work more interesting. \\
$\begin{array}{l}\text { Many complex designs are only possible with the support of parametric design, hence opening up complete new } \\
\text { areas for architectural design creativity. }\end{array}$ \\
$\begin{array}{l}\text { Consistency between parts of a design is covered better when using parametric design. Especially in the early } \\
\text { design stages, initial ideas can change and designs and assumptions have to be reconsidered in turn. Parametric } \\
\text { design can help by keeping designs and requirements consistent throughout the iterative design process. }\end{array}$ \\
Parametric design will allow architects to generate more alternatives by structurally exploring the design space. \\
\hline $\begin{array}{l}\text { Parametric design will allow for the inclusion of different technical and social constraints within the process of } \\
\text { systematically generating alternatives. This will support the creative design process as architects will not need to } \\
\text { worry about developing unfeasible solutions. } \\
\text { Parametric design will allow architects to evaluate alternatives according to multiple criteria for which indicators } \\
\text { can be quickly calculated according to specific parameter settings of a generated alternative. }\end{array}$
\end{tabular}

\subsection{Concept Modelling Ontology (CMO)}

CMO is a standard based in Semantic Web and inheriting its benefits. CMO with Extensions is an extension of $\mathrm{CMO}$ that also supports storing and exchanging parametric design. CMO-technology connects the parametric design tool to BIM. Using semantic BIM and $\mathrm{CMO}$ within parametric design tools can allow architects to overcome the limitations of the traditionally purely geometric parametric modellers. Architects will be able to generate and evaluate alternatives throughout each stage of the design process using intuitive natural language interfaces. This will substantially increase the amount of design alternatives that can be generated and evaluated.

CMO is a reusable, generic ontology that enables semantic parametric design modelling capabilities. Semantic Web (W3C) technology, building on the $\mathrm{W} 3 \mathrm{C}$ OWL language, is the perfect medium for developing large-scale, webbased, multi-stakeholder information structures and ontologies. These structures and ontologies can be used for knowledge management and/ or data exchange.

Some essential modelling capabilities (ingredients) are modelled once only in $\mathrm{CMO}$ and then can be reused every time needed. CMO is imported in all CMO/OWL2-compliant end- user ontologies. CMO is a fully open standard that can be freely reused without any constraints as it was developed in several EC supported research projects (Odysseus, V-Con, EcoDistrict).

Architects can benefit from implementing $\mathrm{CMO}$ in the following ways as shown in Table 3.

\subsection{Virtual and Augmented Reality (VR/AR)}

Graham et. al (2013) explain augmented reality (AR) as the material/virtual nexus mediated through technology, information and code, and enacted in specific and individualised space/time configurations, that is the physical, real-world environment whose elements are augmented (or supplemented) by computergenerated sensory input such as sound, video, graphics or GPS data. By contrast, virtual reality replaces the real world with a simulated one (Petrick et al. 2002). With the help of advanced AR technology (e.g. adding computer vision and object recognition) the information about the surrounding real world of the user becomes interactive and digitally manipulative. Artificial information about the environment and its objects can be overlaid on the real world.

The development of custom VR/AR interfaces upon BIM allow for the seamless representation of parametrically generated design solutions to all important stakeholders at 
Table 3. Advantages for architects engaged in CSO of CMO

CMO enables reuse of parametric design and libraries in several software packages

$\mathrm{CMO}$ is an open standard and vendor independent. Hence, using CMO will allow cooperation between partners that work with software from different vendors. Especially SME's will benefit from such vendor independence enabling them to work more flexibly on different projects.

As SME's do not have the power to influence large software vendors, vendor dependency is an important issue. Becoming vendor independent by using CMO is a very important stepping stone for increasing the competitive advantage of European architects.

a specific stage of the design. Transaction and opportunity costs of design content and planning meetings can thus be drastically reduced.

Virtual and Augmented Reality technologies tie together the semantic and parametric design technologies and make them intuitively and seamlessly available within participatory (PD) and collaborative (CD) process. Virtual reality will support the clear representation of the many design solutions that can be generated by parametric modelling applications. To this end, VR can provide detailed representations of technical details for very specific design activities, as well as holistic representations of design alternatives for communication tasks with stakeholders within the value chain. Contributing to the possibilities of VR/AR will allow moving design activities to the field to seamlessly integrate the existing conditions of the urban fabric that poses the main constraints to architectural creativity. AR will allow for the integration of information about existing constraints, but also for directly developing design solutions while creatively interacting with these constraints.

Architects may benefit from implementing VR/AR in the following ways as shown in Table 4.

\section{NETWORK BUSINESS MODEL TO PROVIDE ARCHITECTS WITH INNOVATIVE COLLABORATIVE DESIGN TECHNOLOGY (CDT) SOLUTIONS}

Besides customizing, configuring and demonstrating emerging CDT solutions for CSO housing development, PROFICIENT also proposes a business model to bring the knowledge and tools developed to the target group of European architects. The business model focuses on the development of a comprehensive and easy to handle platform (web portal) for provision, learning and exchanging state-of-the-art CDT solutions. An e-marketplace will be part of

\section{Table 4. Advantages for architects engaged in CSO of VR/AR}

VR/AR enhance the quality of communication by replacing the typically used 2D drawing print outs that are not easy
to handle and only provide a limited information density. The enhanced quality of communication VR/AR offers will
speed up the decision making processes and allow for deep understanding of the expected result by experts and clients.
VR/AR allow for design adjustments before they create extra planning costs and investments costs for double work of
other experts involved, such as, for example, structural engineers who regularly follow the workflow of the architect.
VR allow architects to visually evaluate different parametrically created alternatives according to both, aesthetic and
technical objectives.
VR allow the inclusion of a wide variety of specialist and non-specialist stakeholders in the design process.
AR bring the design process to the field providing architects and their stakeholders improved possibilities for including
the construction site and existing building condition within their design activities. 
the platform, to allow technology providers to develop and market innovative CDT solutions based upon a combination of BIM, semantic and parametric modelling, as well ask advanced (mobile) AR/VR user interfaces. The e-marketplace will allow for a quick and easy uptake ofCDT solutions by architects. Bringing innovative technology providers and architects together will fully allow architects to leverage the potential CDT solutions offered in order to widen creative possibilities and improve efficiency. At the same time, the contents of this platform and e-marketplace will be used for embedding CDT solutions in practice and education through Continuous Professional Development (CPD) for professionals and university curricula for architecture students.

As design activities around the built environment become technically complex (for example by increasing requirements for energy life-cycle behaviour) and socially complex (due to the development of a more and more pluralistic society), architects need to deliver creative design solutions that include integrated performance requirements, which is a difficult task without the possibility of using advanced CDT solutions. The intended PROFICIENT e-marketplace will foster exchanges between architects and providers of innovative CDT solutions and will become a catalyst for collaboration opportunities, flexible partnerships and joint business models between the architectural design SMEs, construction partners and CDT solution providers. The PROFICIENT platform will accommodate dynamic matching processes between designer/ user requirements and CDT solutions and the associated businesses respectively.

At the e-marketplace ICT-suppliers offer their commercial CDT solutions and architects/ ICT-clients can communicate their specific questions, requests and requirements. Clear communication will allow shaping flexible partnerships and joint business models between the architectural design SMEs, construction stakeholders and CDT solution providers. The e-marketplace will be used to implement new ways of collaboration based on project collaboration (ICT-supply just for specific projects), SaaS-contracts (Software as a Service, preventing large investments in software and hardware infrastructure), shared investments (ICT-investments shared by the building consortium) and partnerships between architects and ICT-providers based on a jointly adapted business model. In essence, new forms of collaboration will be made available on the PROFICIENT-platform between architects and technology providers.

- The PROFICIENT business model for the leveraging of innovative ICDT-solutions to European architects consists of the following elements:

- An e-marketplace where commercial ICT-suppliers offer their products and services to the target group.

- Demonstrations of the potential of emerging CDT solutions for architects by way of impact case studies.

- Free downloads of open standard basic software developed in previous EC-supported research projects (IFC toolboxes/CMO tools/Open Source BIM Server).

- Commercial software applications and end-user tools that are highly customizable and flexible adjustable.

- E-learning material to be used for self-instruction and CPD (Continuing Professional Development) and in university curricula.

- Creative business strategies to accommodate the limited investment resources of architecture SMEs based on smart partnerships between architects and ICT-suppliers.

- Different examples that show the possibilities in practise:

- An example of a collaborative application that supports users and architects to jointly design floor plans.

- An example of a core design for a so-called CSO (Collective SelfOrganized) Housing project will show how a CAD-design is translated into 


\section{Table 5. Advantages for architects engaged in CSO of the PROFICIENT business Model}

\begin{tabular}{l}
\hline $\begin{array}{l}\text { Direct, fast and unambiguous communication with all stakeholders, which enables the architect to better direct the } \\
\text { design efforts towards societal and organizational needs of clients. }\end{array}$ \\
\hline $\begin{array}{l}\text { Direct and fast access and use of various sources of knowledge, solutions, ideas and innovations for full and holistic } \\
\text { architectural and design integration as early in the process as possible. This allows for the fast but accurate exploration } \\
\text { and (re)setting of design parameters together with all stakeholders through 'many-to-many' (visual) communication. }\end{array}$ \\
\hline $\begin{array}{l}\text { Digital information exchange enabling international collaboration between different designers and streamlined } \\
\text { communication between the architects' offices and building sites. These possibilities for digital information exchange } \\
\text { will increase the international competiveness of European architects. }\end{array}$ \\
\hline $\begin{array}{l}\text { Quick and accurate feedback on the performance of design alternatives. Such feedback will significantly increase } \\
\text { building performance by improving the design process for a single building and by providing advanced possibilities } \\
\text { for learning across a number of building design projects. }\end{array}$ \\
\hline State-of-the-art stylish and highly visual company, portfolio and design presentations. \\
\hline $\begin{array}{l}\text { Delivery of end-user tools, connected to design and BIM, enabling post construction services extended to the } \\
\text { exploitation phase that can be offered by architects. }\end{array}$ \\
\hline
\end{tabular}

a BIM-model, how the end-user can use the parametric tool to adapt the design of his/her particular house to individual demands.

- An example of the application of virtual and augmented reality in a refurbishment design to project new design alternatives onto the existing situation for decision making, clash prevention and planning of logistic operations.

- An example of a 3D laser will show how highly accurate representations of existing conditions can be integrated in VR environments for architectural design.

- An example of collaborative work within a virtual environment will show possibilities for how ICT-solutions can support creative design in cases participants of the design process are not co-located.

These elements will result in the following ways as shown in Table 5.

\subsection{Example: Use Illustration - IFD/CSO-Housing}

The potential, advantages and benefits of the CDT solutions will be shown in an illustrative example. We have chosen a modular building system, also known as IFD (Industrialised Flexible and Durable Building) to develop the example. The state-of-the-art concept of IFD solves the fragmentation problem and moves the construction industry towards a customerfocused production and project delivery. In PROFICIENT, the IFD-concept is transformed into a business concept that will realise the application for CSO-housing, in combination with a maximum involvement of local SMEs, and the application of energy-efficient housing systems. The core of the building concept is the standardised production of components and structural frame, coordinated installation/ assembly services by SMEs, and flexible infill by the CSO homeowners with the support of local SMEs.

\subsection{Flexibility Options}

Table 6 below shows how the illustration will address the required flexibility by the end-user, and which parts of the basic design can be adapted by the parametric design tool: 
Table 6. Addressing the flexibility requirements of end-users through BIM

\begin{tabular}{|l|l|l|}
\hline \multicolumn{1}{|c|}{ Flexibility Aspect } & \multicolumn{1}{c|}{ Clarification } & \multicolumn{1}{c|}{ Parametric } \\
\hline Size/type & Choose from limited list & No \\
\hline Internal lay-out & Choose from examples; adaptable within limitations & Lay-out \\
\hline Heating/cooling system & $\begin{array}{l}\text { Select from e-marketplace; specified requirements/ } \\
\text { limitations }\end{array}$ & No \\
\hline Kitchen/bathroom equipment & $\begin{array}{l}\text { Select from e-marketplace; specified requirements/ } \\
\text { limitations }\end{array}$ & Lay-out \\
\hline Roof extensions & Choice of dormers; roof windows (e-marketplace) & No \\
\hline Floor space extensions & $\begin{array}{l}\text { Room enlargement; extra room by local contractor } \\
\text { or DIY }\end{array}$ & Yes; 3D \\
\hline Conservatory & E-marketplace & No \\
\hline Finishing & $\begin{array}{l}\text { Paintwork; floor/wall/ceiling/façade finishing } \\
\text { (e-marketplace) }\end{array}$ & No \\
\hline
\end{tabular}

\section{DEVELOPMENT OF THE ILLUSTRATIVE CASE}

In order to explore the usefulness of the BIM approach for CSO housing processes a hypothetical, or illustrative, case study has been developed. By mapping the process by which architects can work in this iterative way, with self-organised collective communities who wish to be involved in all stages of the design process the potential of this model for improving the CSO design process can be clarified.
For this example, an Industrial and Flexible Design (IFD) building system has been assumed. In designing the tool, the following step-by-step stages have been incorporated (Table 7).

The illustration outlined below, offering a three-phase modular model is offered to indicate how the tool will be integrated into the iterative design process with CSO clients. Screen-shots are incorporated to provide a clear indication of how this will be used with clients.

\section{Table 7. Stages in the design of the on-line BIM tool}

\begin{tabular}{|l|}
\hline Design IFD concept (drawings if possible already transferred to basic native BIM) \\
\hline Transformation of architectural design into BIM-open standard IFC and parametric CMO \\
\hline Component and finishing options; development of option lists \\
\hline Connection of option lists to e-marketplace by semantic web \\
\hline Parametric adaptation of lay-out \\
\hline Integration of options chosen and lay-out adaptation in existing BIM \\
\hline VR-representation of integrated design \\
\hline Energy performance calculation of integrated design; energy cost overviews \\
\hline Integration of individual houses/designs into a 3D-view on street and district \\
\hline Integration of energy performance to district level as input for ESCO \\
\hline Cost calculations on individual and district level \\
\hline Upload ofBIM-data model to DEMORE Suite; production of life cycle management information like maintenanceplans \\
\hline
\end{tabular}




\subsection{PHASE 1: Select the Land and Shape Your Building}

\subsubsection{Actions}

Implementation of CSO Community > Land selection and acquisition (from a set of opportunities provided by the e-Marketplace (e-Mp) $>$ Choice of the building/buildings type and their configuration in the land.

\subsubsection{Tool}

Simple configurator or sketcher (module 1) (see Figure 1).

\subsection{PHASE 2: Design Your Dwelling}

\subsubsection{Actions}

Development and definition of end-users' choices > Implementation of matrices of dwelling > Implementation of dwellings $>$ Development of Concept Design of building/buildings.

\subsubsection{Tool}

Simple configurator or sketcher (module 2) (see Figure 2).

\subsection{PHASE 3: Define the EEB Strategy and Complete Your Choices}

\subsubsection{Actions}

Implementation of BIM model $>$ Definition of energy-efficiency strategy - Completion and finalization of design solution assessing costs (applying the Participatory and Concurrent Design methodology).

\subsubsection{Tool}

$\mathrm{BIM}, \mathrm{IFC}, \mathrm{CMO}$ and parametric design tool configurator (see Figure 3).

\section{DISCUSSION AND CONCLUSION}

The incorporation of the online CDT BIM tool into the participatory design process can be seen to provide an effective tool for the implementation of streamlined co-design between architects, other contractors and CSO communities.

The parametric possibilities of the use of BIM software in this case allows for the rapid improvement of designs based on the ongoing evaluations made by client groups. The possibility of providing clients with advanced models and simulations offers a common visual language to both client and architect, whilst allowing constraints put in place by regulations and planning frameworks to be incorporated into the design. Considering the value-base of many CSO communities, the model also allows client limitations, such as for communal and shared facilities, EeB design and green infrastructure, to be built into the design process.

The outcome of PROFICIENT in terms of economic benefits for architectural firms is to develop beyond the existing service-oriented business model. There is a growing demand for CSO housing in the new building sector and, regarding climate protection targets promoted by the EU and national governments, it is expected that this approach will contribute to the provision of a climate-neutral housing stock. It is expected that in the near future this orientation might cause a growing demand in the retrofitting housing sector, as well. Many architectural practices are planning to enhance the services provided until now in order to match with the demands of these new market opportunities. The influence of the new model, created on the basis of PROFICIENT findings, on the core architectural service offer has the potential to radically redesign the existing business model. This paper has therefore concentrated on the process of BIM modelling, designed through PROFICIENT that will impact particularly on architectural practice.

This process outlined in this paper indicates that the processes of configuration using the semantic web based platform can ensure 
Figure 1. Simple configurator or sketcher (Module 1)

\begin{tabular}{|c|c|}
\hline 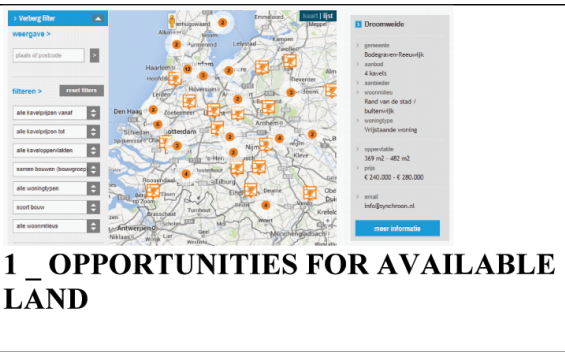 & $\begin{array}{l}\text { Actions } \\
\text { Collection of information about } \\
\text { available lands. } \\
\text { Uploading of information in the e-Mpl } \\
\text { website. } \\
\text { Access of CSO community to the } \\
\text { opportunities } \\
\text { Key actors } \\
\text { e-Mp management } \\
\text { CSO community/end-users }\end{array}$ \\
\hline 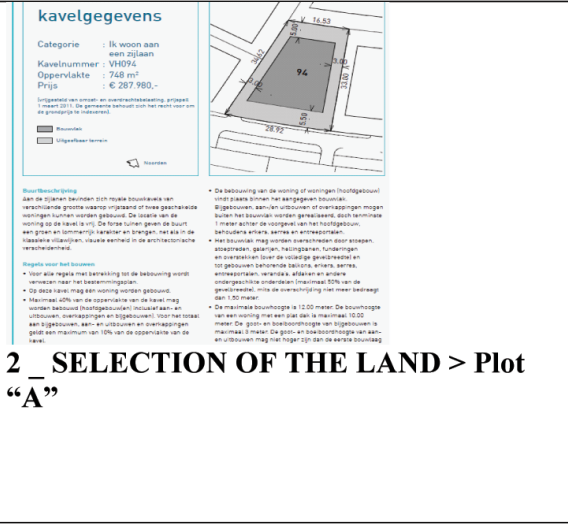 & $\begin{array}{l}\text { Actions } \\
\text { Uploading of detailed information about } \\
\text { the available lands on an "e-Mp } \\
\text { catalogue". } \\
\text { This action could be made with public or } \\
\text { private agencies or other subjects which } \\
\text { manage this information. } \\
\text { Selection of the land/plot by the CSO } \\
\text { community } \\
\text { The procedure could be quite different } \\
\text { depending on the Country and/or the } \\
\text { subject that drives the process. } \\
\text { Key actors } \\
\text { e-Mp management } \\
\text { CSO community/end-users }\end{array}$ \\
\hline $\begin{array}{l}\text { LOGIES } \\
\text { T "A"> }\end{array}$ & $\begin{array}{l}\text { Actions } \\
\text { For each land a matrix of feasible } \\
\text { typologies of buildings is indicated and } \\
\text { described into the e-Market catalogue. } \\
\text { Implementation of a simple } \\
\text { configurator or sketcher which will } \\
\text { allow the end-users to understand } \\
\text { opportunities and limits of each typology } \\
\text { (for example: } n \text {. and type of dwellings, } \\
\text { distribution of staircases, etc.) before } \\
\text { shaping the building (or buildings) in the } \\
\text { land. } \\
\text { Key actors } \\
\text { Professionals (e-Mp managers, facilitators, } \\
\text { architect) } \\
\text { CSO community/end-users }\end{array}$ \\
\hline 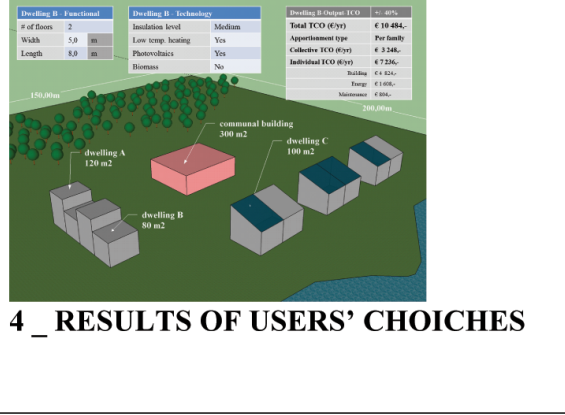 & $\begin{array}{l}\text { Actions } \\
\text { Working on a set of basic (feasible) given } \\
\text { schemes the end-users configure their } \\
\text { preferred solution compatible both with } \\
\text { their requirements and with the city plan, } \\
\text { legislation, technical standards, etc. } \\
\text { The end-users "design" their houses, } \\
\text { common services and external spaces } \\
\text { implementing a basic scheme to be } \\
\text { developed by the architect. } \\
\text { Key actors } \\
\text { CSO community/end-users }\end{array}$ \\
\hline
\end{tabular}


Figure 2. Simple configurator or sketcher (Module 2)

\begin{tabular}{|c|c|}
\hline $\begin{array}{l}1 \text { DEVELOPMENT OF USERS' CHOICE } \\
\text { AND EXTENSION OF CONFIGURATOR } \\
\text { TOOLS }\end{array}$ & $\begin{array}{l}\text { Actions } \\
\text { Development of configurations } \\
\text { chosen by end-users and } \\
\text { implementation of "feasible" } \\
\text { solutions compatible with the land } \\
\text { restrictions, urban plan, standards, } \\
\text { legislations, etc. } \\
\text { Key actors } \\
\checkmark \text { Professionals (e-Mp managers, } \\
\quad \text { software developers, architect) }\end{array}$ \\
\hline 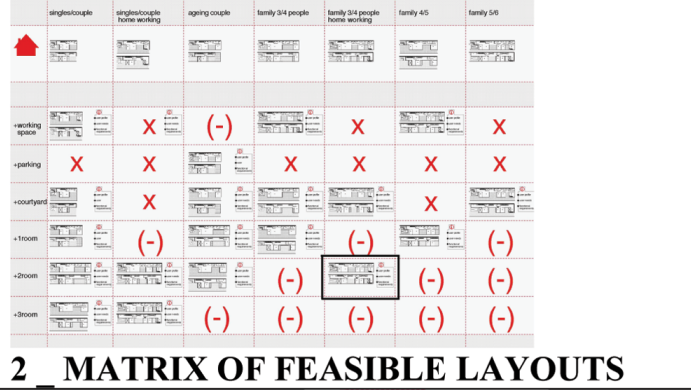 & $\begin{array}{l}\text { Actions } \\
\text { Implementation of a matrix of } \\
\text { layouts compatible with the } \\
\text { building configuration (or } \\
\text { configurations) defined in the } \\
\text { previous step. } \\
\text { Key actors } \\
\checkmark \text { Professionals (e-Mp managers, } \\
\quad \text { software developers, architect) }\end{array}$ \\
\hline $\begin{array}{l}3 \text { DESIGN OF DWELLING USING THE } \\
\text { CONFIGURATOR }\end{array}$ & $\begin{array}{l}\text { Actions } \\
\text { Using the configurator the end-users } \\
\text { can change the lay-out within a } \\
\text { given number of possibilities (they } \\
\text { can operate, for example, on the } \\
\text { dimension, shape and destination of } \\
\text { rooms but not on the position of } \\
\text { kitchen and toilets that depends on } \\
\text { technical restrictions). } \\
\text { Key actors } \\
\checkmark \text { End-users }\end{array}$ \\
\hline $\begin{array}{l}4 \text { IMPLEMENTATION OF CONCEPT } \\
\text { DESIGN }\end{array}$ & $\begin{array}{l}\text { Actions } \\
\text { Implementation of the first } \\
\text { architectural solutions based on the } \\
\text { end-users' choices. } \\
\text { Solutions are developed by the } \\
\text { architect discussing with the end- } \\
\text { users (application of Participatory } \\
\text { Design approach) } \\
\text { Key actors } \\
\checkmark \text { End-users with architect's assistance }\end{array}$ \\
\hline
\end{tabular}


Figure 3. BIM, IFC, CMO and parametric design tool configurator

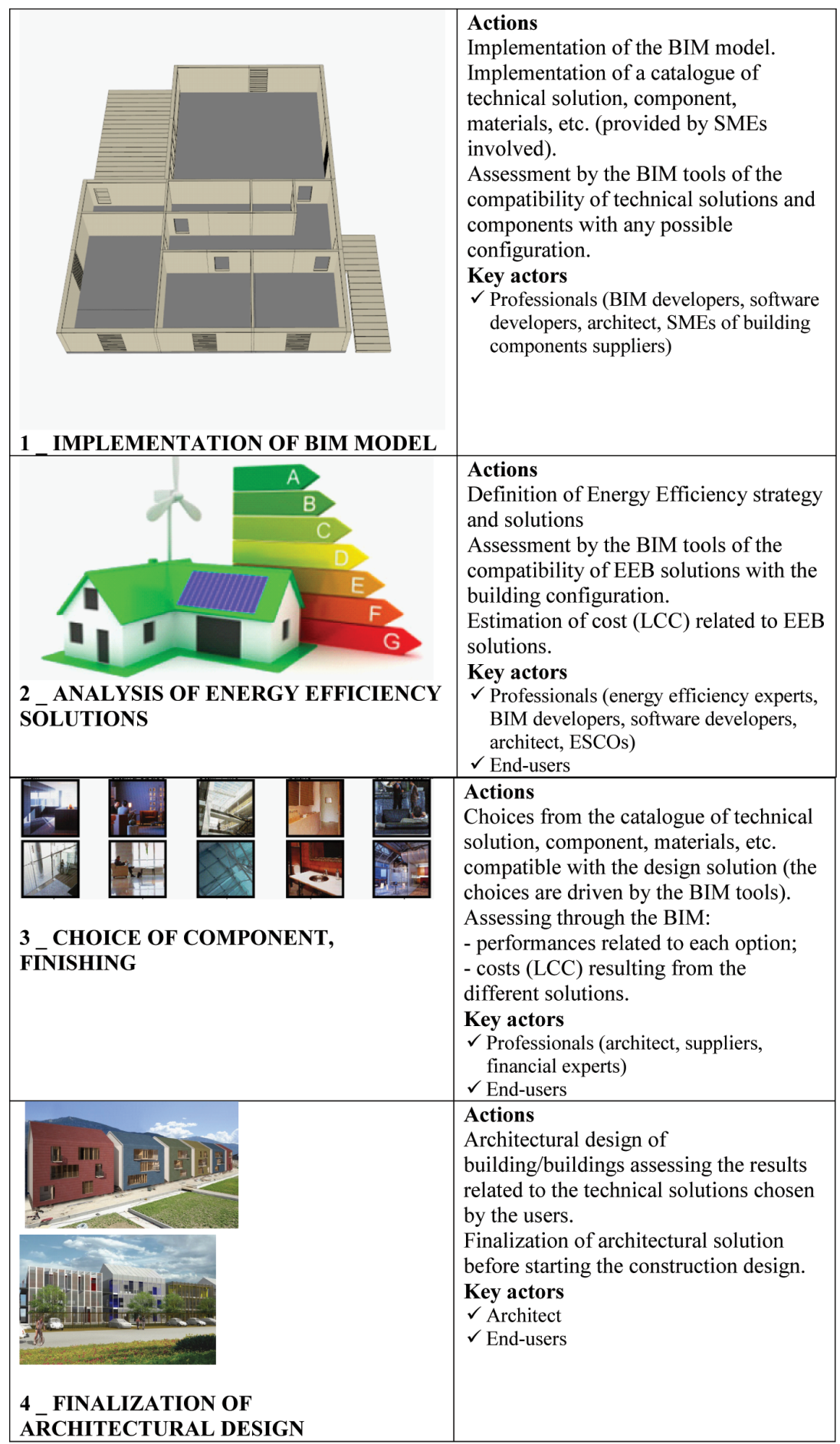


the architectural proposition can be offered more efficiently and therefore economically. Tailoring solutions to market and client needs is a key success factor of the CSO approach and the platform presented here ensures that the complexity of working with collectives of clients and the iterative nature of that process can be incorporated. Without this tool it will be complicated to create an efficient, effective and profitable business model, considering the complicated nature of CSO housing.

This paper has shown that the model proposed here can extend the reflective conversation beyond the individual designer and the design situation (Schon, 1984), to incorporate collective inputs into the design in CSO housing communities. Thus the model allows an iterative process to be integrated, enabling the 'idealised' design sequence outlined by Valkenburg \& Dorst (1998) and Zerjav et al. (2013). The paper supports Hartmann et al.'s assertion that the architectural design process can be supported by the application of BIM. As Yan et al. (2011) argue, BIM can aid communication between client and architect, which is especially important in a CSO design process, given the need to communicate and co-design with group, rather than individual, clients. As Jernigan (2008) outlines, the exchange of information at different stages of the design between clients and architects is increasingly problematic, as EeB requirements and the value base of client groups needs to be incorporated and end users become increasingly participative within the process. This paper has introduced a method and process framework that incorporates CDT, BIM and AR/VR modelling into the participatory design process, addressing the gap identified in the provision of such systems for CSO housing.

As this model is developed and refined, further research on applicability-in-practice is called for. The efficiency gains for architects and client groups should be empirically tested through case examples. The willingness of architectural practices to engage with the tools and the networked business model that PROFICIENT offers should also be explored.
In conclusion, the CDT/BIM model presented in this paper suggests a new solution for co-design in this emerging field of residential housing that indicates it will address many of the constraints that can arise when engaging with multi-stakeholder architectural design in the CSO housing field.

\section{ACKNOWLEDGMENT}

The results and developments reported are partly based on research in "PROFICIENT - SME network business model for collective self-organised processes in the construction and retrofit of energy-efficient residential districts". This research received funding from the European Community's Seventh Framework Programme under project number 312219; call identifier FP7-2012-NMP-ENV-ENERGY-ICT-EeB.

\section{REFERENCES}

AIA-American Institute of Architects. (2013). Guide to AIA Contract Documents for Small Projects. Retrieved $5^{\text {th }}$ June, 2014 from http:/www.aia.org/ groups/aia/documents/pdf/aiab098207.pdf

AlQahtany, A., Rezgui, Y., \& Li, H. (2013). A proposed model for sustainable urban planning development for environmentally friendly communities. Architectural Engineering and Design Management, 9(3), 176-194. doi:10.1080/17452007.2012.738042

Amstalden, R. W., Kost, M., Nathani, C., \& Imboden, D. M. (2007). Economic potential of energy-efficient retrofitting in the Swiss residential building sector: The effects of policy instruments and energy price expectations. Energy Policy, 35(3), 1819-1829. doi:10.1016/j.enpol.2006.05.018

(in press). Amstel, van F. M. C, Zerjav V., Hartmann T., Voort, van der M.C \& Dewulf G. [Expanding the representation of user activities. Building Research and Information.]. $P M \& R$.

Boland, R. J. Jr, Lyytinen, K., \& Yoo, Y. (2007). Wakes of Innovation in Project Networks: The Case of Digital 3-D Representations in Architecture, Engineering, and Construction. Organization Science, 18(4), 631-647. doi:10.1287/orsc.1070.0304 
Clevenger, C., Haymaker, J. R., \& Ehrich, A. (2013). Design exploration assessment methodology: Testing the guidance of design processes. Journal of Engineering Design, 24(3), 165-184. doi:10.1080 /09544828.2012.698256

DCLG - Department for Communities \& Local Government. UK (2014)Self Builders. Retrieved 6th June 2014 from http://www.gov.uk/government/ policies/increasing-the-number-of-available-homes/ supporting-pages/self-builders

Dorst, K. (2011). The core of 'design thinking' and its application. Design Studies, 32(6), 521-532. doi:10.1016/j.destud.2011.07.006

Evgeniou, T., Fonstad, N., Merdikawati, N., \& Rodriguez-Montemayor, E. (2013) Building Competitiveness and Business Performance with ICT: How Investments in New Technologies Can Make Companies More Competitive (working paper), Fontainebleau, France, INSEAD.

Gane, V., \& Haymaker, J. (2012). Design Scenarios: Enabling Requirements-Driven Parametric Design Spaces. Advanced Engineering Informatics, 26(3), 618-640. doi:10.1016/j.aei.2012.04.008

Gerőházi E., Hegedüs J. \& Szemző H. (2014) CSO housing market study PROFICIENT project report $2: 2$.

Graham, M., Zook, M., \& Boulton, A. (2013). [REMOVED HYPERLINK FIELD] Augmented reality in urban places: Contested content and the duplicity of code. Transactions of the Institute of British Geographers, 38(3), 464-479. doi:10.1111/j.14755661.2012.00539.x

Guy, S., \& Shove, E. (2000). A sociology of Buildings: Constructing Knowledge, designing practice. London: Routeledge.

Hartmann, T., \& Fischer, M. (2007). Supporting the Constructability Review with 3D/4D Models. Building Research and Information, 35(1), 70-80. doi:10.1080/09613210600942218

Hartmann, T., Gao, J., \& Fischer, M. (2008). Areas of application of 3D and 4D models on construction projects. Journal of Construction Engineering and Management, 134(10), 776-785. doi:10.1061/ (ASCE)0733-9364(2008)134:10(776)

HOAI. (1999). Honorarordnung für Architekten und Ingenieure. C.H. Beck Verlag München.

Jernigan, F. E. (2008). Big BIM, little bim (2nd Edition) Salisburg, Side Press.
Luck, R. (2009). Does this compromise your design?: Interactionally producing a design concept in talk. CoDesign, 5(1), 21-34. doi:10.1080/15710880802492896

MacDonald M., Rødsjø, A, Soetanto, D. \& McKeever, E. (2014) Review of existing loans, incentives and subsidies for Energy Efficiency PROFICIENT project report 5.2.

Mirza \& Nacey Research. (2008) The Architectural Profession in Europe - A Sector Study Report commissioned by the Architects' Council of Europe.

Mohammadali, H., Allameh, E., de Vries, B., Timmermans, H., Jessurun, J., \& Mozaffar, F. (2014). Smart-BIM virtual prototype implementation. Automation in Construction, 39, 134-144. doi:10.1016/j. autcon.2013.07.004

Olsson, P., Folke, C., \& Berkes, F. (2004). Adaptive co-management for building social-ecological resilience. Environmental Management, 34, 75-90. doi:10.1007/s00267-003-0101-7 PMID:15383875

Petric, J., Maver, T. W., Conti, G., \& Ucelli, G. (2002) Virtual reality in the service of user participation in architecture. Paper presented to the CIB W78 conference: "Distributing Knowledge in Building", Denmark.

Schön, D.A. (1984). The reflective practitioner: How professionals think in action. New York: Basic Books.

Sebastian, R. (2006). Evaluating a proposed approach for managing collaborative design in the conceptual design phase. Architectural Engineering and Design Management, 2(3), 216-224.

Sebastian, R., Haak, W., \& Vos, E. (2009) BIM Application for Integrated Design and Engineering in Small-Scale Housing Development: A Pilot Project in the Netherlands Paper presented at the International Symposium CIB-W096: "Future trends in Architectural Management", Taiwan.

Sebastjan, M., Turk, Ž., \& Dolenc, M. (2014). Component based engineering of a mobile BIM-based augmented reality system. Automation in Construction, 42, 1-12. doi:10.1016/j.autcon.2014.02.011

Smith, M. (2014) What is BIM? Retrieved $4^{\text {th }}$ June 2014 from http://www.thenbs.com/bim/what-isbim.asp

Stumpf, S. C., \& McDonnell, J. T. (2002). Talking about team framing: Using argumentation to analyse and support experiential learning in early design episodes. Design Studies, 23(1), 5-23. doi:10.1016/ S0142-694X(01)00020-5 
Valkenburg, R., \& Dorst, K. (1998). The reflective practice of design teams. Design Studies, 19(3), 249-271. doi:10.1016/S0142-694X(98)00011-8

Welle, B., Haymaker, J., Fischer, M., \& Bazjanac, V. (2014). CAD-Centric Attribution Methodology for Multidisciplinary Optimization Environments: Enabling Parametric Attribution for Efficient Design Space Formulation and Evaluation. Journal of Computing in Civil Engineering, 28(2), 284-296. doi:10.1061/(ASCE)CP.1943-5487.0000322
Yan, W., Culp, C., \& Graf, R. (2011). Integrating BIM and gaming for real-time interactive architectural visualization. Automation in Construction, 20(4), 446-458. doi:10.1016/j.autcon.2010.11.013

Zerjav, V., Hartmann, T., \& Achammer, C. (2013). Managing the Process of Interdisciplinary Design: Identifying, Enforcing, and Anticipating Decision Making Frames. Architectural Engineering and Design Management, 9(2), 121-133. doi:10.1080/ 17452007.2013.775106 